\title{
Properties of cement with addition of volcanic tuffs and zeolite
}

\author{
Ekaterina Potapova ${ }^{1}$, Yury Krivoborodov ${ }^{1}$, Svetlana Samchenko, ${ }^{2,}$, and Tamara \\ Kouznetsova ${ }^{1}$ \\ ${ }^{1}$ Mendeleev University of Chemical Technology of Russia, Moscow, Russia \\ ${ }^{2}$ Moscow State University of Civil Engineering, Yaroslavskoe shosse, 26, Moscow, 129337, Russia
}

\begin{abstract}
The article consists of the research results of influence of zeolite and volcanic tuff on the processes of hydration of blended cements and their properties. The studied tuffs are characterized by lower pozzolanic activity in comparison with microsilica and metakaoline, however, their addition to cement provides the production of sulfateresistance, cold-resistance blended cement with higher strength in comparison with Portland cement without additives.
\end{abstract}

\section{Introduction}

The usage of natural mineral additives and waste of industry is known for an along time. This is due to the fact that the use of different additives reduces the energy consumption for the production of cement, improves the environment, decreases emissions of greenhouse gases. The usage of natural materials, such as pozzolana, tripoli, flask and diatomite is known since the creation of Portland cement. For many decades granulated slag, fly ash, silica fume are used at cement production. In recent years much attention is paid to the metakaoline as an active mineral additive [1-8]. At present production of blended cements is one of the priorities that was mentioned at the past International Congresses on the chemistry and technology of cement in Brazil [9], Spain [10], China [11] and other conferences [12-14]. It is noted that the era of the production of Portland cement without additives cement ended, in the future low-clinker cements and concretes with low cement consumption will be developed. Such way of development of building materials mainly due to the necessity to reduce energy consumption on their production, reduce emissions, preserve natural resources and prevent the rejection of land for waste disposal. However the usage of additives in cement production is not only limited by the increase of its production at lower energy consumption, but mainly their usage assists to the improvement of cement stone structure, which leads to an increase of strength characteristics, frost resistance, corrosion resistance, i.e. its durability. Despite the large number of researches before recommending any supplements to industrial use, it is necessary to carry out the relevant studies.

The aim of our research was to study the hydration and hardening of cements consist of volcanic additives, development of optimum compositions of cement and study of their

*Corresponding author: $\underline{\text { samchenko@,list.ru }}$ 
properties. Zeolite and volcanic tuffs - rocks, developed in areas of volcanic activity; include an aqueous aluminosilicates in which the "zeolite" water can be removed by heating and re-absorbed by the mineral in a wet environment without distruction its crystalline structure. Peculiarity of composition and structure of zeolites, their good grindability, significant volumes of raw material resources determine the perspective of their usage in cement and concrete technology.

\section{Experimental}

As objects of research zeolite-containing rocks and volcanic tuffs were taken. For comparison such additives as blast furnace slag, silica fume and metakaoline were used too. The chemical composition of all materials is shown in table.1.

Table 1. Chemical composition of used materials, wt \%

\begin{tabular}{|l|c|c|c|c|c|c|c|c|c|}
\hline Materials & $\begin{array}{c}\text { Abbrevia } \\
\text { tion }\end{array}$ & L.O.I. & $\mathbf{S i O}_{2}$ & $\mathbf{A l}_{2} \mathbf{O}_{3}$ & $\mathbf{F e}_{2} \mathbf{O}_{3}$ & $\mathbf{C a O}$ & $\mathbf{M g O}$ & $\mathbf{N a}_{2} \mathbf{O}$ & $\mathbf{S O}_{3}$ \\
\hline PC clinker & PCC & 0.52 & 21.20 & 6.22 & 3.70 & 64.77 & 1.31 & 1.20 & 0.46 \\
\hline $\begin{array}{l}\text { Metakaoli } \\
\text { ne }\end{array}$ & $\mathrm{MK}$ & 0.55 & 53.10 & 43.13 & 2.48 & 0.40 & 0.30 & 0.15 & - \\
\hline $\begin{array}{l}\text { Silica } \\
\text { fume }\end{array}$ & $\mathrm{SF}$ & - & 94 & 1.2 & 0.7 & 0.2 & 0.2 & 2.0 & - \\
\hline Slag & $\mathrm{Sl}$ & 1.72 & 33.60 & 13.31 & 2.38 & 41.60 & 8.8 & 0.26 & 0.10 \\
\hline $\begin{array}{l}\text { Zeolite } \\
\text { tuff }\end{array}$ & $\mathrm{ZT}$ & 9.44 & 67.22 & 12.99 & 1.45 & 2.33 & 0.86 & 3.65 & 0.06 \\
\hline $\begin{array}{l}\text { Volkanic } \\
\text { tuff }\end{array}$ & $\mathrm{VT}$ & 2.15 & 50.93 & 18.55 & 8.67 & 9.96 & 5.92 & 2.15 & 3.65 \\
\hline Gipsum & $\mathrm{G}$ & 20.00 & 1.58 & 1.42 & 0.50 & 31.2 & 0.61 & 0.30 & $\begin{array}{c}4.5 \\
0\end{array}$ \\
\hline
\end{tabular}

Metakaoline $(M K)$ - industrial product, specific surface $S_{\mathrm{sp}}=15000 \mathrm{~cm}^{2} / \mathrm{g}$, silica fume $(\mathrm{SF})$ - industrial product with a density of $500 \mathrm{~kg} / \mathrm{m}^{3}$ and specific surface $\mathrm{S}_{\mathrm{sp}}=15000$ $\mathrm{cm} 2 / \mathrm{g}$. Zeolite tuff and volcanic tuff - natural rocks contain minerals of zeolite group. The first one has a pozzolanic activity of $200 \mathrm{mg} / \mathrm{g} \mathrm{Ca}(\mathrm{OH})_{2}$, the second - low active one(45 $\mathrm{mg} / \mathrm{g}$ ).

Cement samples were prepared by joint milling in laboratory mill Portland cement clinker, $5 \%$ of gypsum and studied additives according to the proportion in table 2 . Grinding all cement samples were made up of sieve residue $\mathrm{R}_{008}=6 \%$.

The strength of the cements were carried out according to national standard GOST 30744-2001. To determine the kinetics of hydration, the products of hydration, structure formation and properties of cement stone well known methods were used: differential thermal analysis (DTA), X-ray diffraction (XRD) and scanning electron microscopy (SEM).

Table 2. The compositions of the studied cements

\begin{tabular}{|l|c|c|c|c|c|c|}
\hline \multicolumn{1}{|c|}{ Sample } & PC & Metakaoline & Silica fume & Slag & Zeolite tuff & Volcanic tuff \\
\hline Control PC & 100 & - & - & - & - & - \\
\hline C-MK & 85 & 15 & - & - & - & - \\
\hline C-SF & 85 & - & 15 & - & - & - \\
\hline C-S1 & 85 & - & - & 15 & - & - \\
\hline C-ZT & 85 & - & - & - & 15 & - \\
\hline C-ZTVT & 85 & - & - & - & 10 & 5 \\
\hline
\end{tabular}

Sulphate resistance was carried out using standard samples $4 \times 4 \times 16 \mathrm{~cm}$ in the ratio of $1: 3$ (cement: sand) and water-cement ratio $\mathrm{W} / \mathrm{C}=0.5$. As corrosive agent $5 \%$ solution of $\mathrm{Na}_{2} \mathrm{SO}_{4}$ was used. After curing for 28 days in water one part of the specimens immersed 
into sulfate solution, the other part was left to harden in water. After 6 months the samples were tested for strength.

To determine the frost resistance of blend cements standard samples were prepared too. After curing in water for 28 days, the samples were subjected according to next procedure: freezing at $-20^{\circ} \mathrm{C}$ for $4 \mathrm{~h}$ and thawing for $4 \mathrm{~h}$ at $+20^{\circ} \mathrm{C}$. Control samples of equivalent age were stored in the water before testing them.

Frost resistance was evaluated by the weight loss of the samples, the coefficient frost resistance was defined by the ratio of the compressive strength after tests of frost resistance to the compressive strength of samples of equivalent age. After each cycle the strength of the samples was determined, the presence of cracks on the samples and the loss of their weight were fixed too.

\section{Results and discussion}

\subsection{Strength of cement stone}

Flexural and compressive strength of blended cements was determined at the age of 3, 7 and 28 days (table. 3 ).

The sample test shows at the same amount of additives to the Portland cement samples have different strength at the same time hardening. It depends on the type of the additives.

The data of table 3 show that the strength of cements consist of metakaoline and silica fume is significantly higher than the strength of cement without the additives at all stages of hardening.

To increase the strength mainly is due to pozzolanic effect of the additives and the filling of pores by hydrated products. So the samples become more dense, a greater amount of CSH gel leads to the strengthening of cement stone.

Table 3. Strength of blended cements

\begin{tabular}{|l|c|c|c|c|c|c|}
\hline \multirow{2}{*}{ Sample } & \multicolumn{3}{|c|}{ Flexural strength, MPa } & \multicolumn{3}{c|}{ Compressive strength, MPa } \\
\cline { 2 - 7 } & $3 \mathrm{~d}$ & $7 \mathrm{~d}$ & $28 \mathrm{~d}$ & $3 \mathrm{~d}$ & $7 \mathrm{~d}$ & $28 \mathrm{~d}$ \\
\hline Control PC & 5.20 & 5.60 & 6.30 & 35.60 & 44.0 & 54,7 \\
\hline C-MK & 6.40 & 7.21 & 8.15 & 40.0 & 49.0 & 62.0 \\
\hline C-SF & 6.10 & 7.35 & 8.00 & 42.3 & 49.7 & 63.5 \\
\hline C-S1 & 4.51 & 5.15 & 6.20 & 28.3 & 42.1 & 50.8 \\
\hline C-ZT & 5.42 & 5.85 & 6.52 & 37.0 & 46.3 & 56.2 \\
\hline C-ZTVT & 5.30 & 5.70 & 6.31 & 36.3 & 45.6 & 54.0 \\
\hline
\end{tabular}

The cements consisted of zeolite and volcanic tuff reach a lesser strength than the cements with the addition of metakaolin and silica fume.

Slag cement shows the slow growth of strength in comparison with the strength growth of cement without additives. The results can be explained by various pozzolanic activity of the used additives. Accordingly, at cement hydration the various types of hydration products formed and their quantity is different.

X-ray analysis of cement hydrated for 28 days shows that the main crystalline phases are non hydrated clinker, portlandite and ettringite. The portlandite peaks $(d=0.267 ; 0.490$; $0.193 \mathrm{~nm}$ ) in blended cements weaker than in comparable control cement. Reduction of portlandite in cement with additives can be explained pozzolanic reaction of additives with calcium hydroxide formed during the hydration of clinker phases. The effect of changing the rate of hydration of cement clinker phases has the other reason too.

At XRD patterns of hydrated paste with metakaolin the intensity of portlandite peaks decreases not only due to more faster hydration but due to the formation of ettringite $(\mathrm{d}=$ 
$0.972 ; 0.560 ; 0.465 \mathrm{~nm}$ ) which peak intensity which increases from 3 to 28 days at XRD patterns. During hydration of cements with zeolite and volcanic tuffs, the intensity of ettringite peaks are much smaller, and they of hydrated cements with the addition of silica fume and slag almost not fixed at XRD patterns.

XRD results are confirmed thermal analysis of hydrated cements. The thermal characteristics for each hydrated products are following: endothermic peak at $90-120^{\circ} \mathrm{C}$ indicates about the presence of C-S-H, peak during $140-150^{\circ} \mathrm{C}$ is due to dehydration of ettringite wide and deep peak at $480-500^{\circ} \mathrm{C}$ is due to the dehydration of portlandite and a small peak in the region $680-9000 \mathrm{C}$ is associated with the decarbonization of calcium which formed from hydtated products reacting with $\mathrm{CO}_{2}$ in the atmosphere.

Endothermic peak at $90-120{ }^{\circ} \mathrm{C}$ (CSH gel) depends on the type of the additive and increases with the during of cement hydration. The value of endothermic peak at the indicated temperature increases during the hydration of all cements with additives in comparison with its size of cement without additives at all stages of hardening. DTA data of hydrated cements differ each other on intensity of endothermic peak at 140-150 0C (ettringite). More clearly the presence of ettringite and the habit of its crystals can be seen from the SEM results. Comparing the microstructure of the control sample cement and cement with slag $(\mathrm{C}-\mathrm{Sl})$ and silica fume $(\mathrm{C}-\mathrm{SF})$ it can be seen the various features. Pores in blended cement stones is more difficult to be found that in control sample. Cements with additive is more dense. The morphology of the hydration products such as ettringite and CSH gel are also different. Large plates of portlandite are distributed in the control cement, in the samples with metakaolin many columnar crystals ettringite, distributed uniformly in the structure of the sample. In slagcemenet crystals of ettringite small, hard to see they in the mass of hydration products. In the sample with zeolite and volcanic tuff crystals ettringite have different habitus. In the pores they are shorter and thinner than near CSHgel, where they seems to be as columnar one. In the sample with silica fume crystals ettringite poorly visible, perhaps it is due to large scale of CSH gel and ettringite crystals dispersed in it uniformly. So, it can be noted that although zeolite tuff less active in comparison of silica fume and metakaoline its addition to Portland cement is effective and even higher than the addition of slag. It can suppose that the "zeolite" component of the cement acts as a natural crystal seed which involves of the inactive volcanic slag into hydration. In addition, the zeolites adsorb excess moisture in the system "cement - water", which also leads to the packed structure of cement stone and to the increase of its strength. A comparative study of hydration of cements with tuff addition showed that it promotes greater amounts of calcium hydrosilicates, decreases the total porosity of cement stone, which causes higher strength of cement stone in comparison with the strength of cement without additives. In addition, the cost zeolite tuff is much lower than that of metakaoline and silica fume, which is also an important factor for its application in cement plants, located in remote areas of the country (Eastern Siberia, Far East, Kamchatka). Take into account these factors further studies were carried out using cements containing in its composition zeolite (C-ZT) and volcanic tuff (C-ZTV).

\subsection{Sulfate resistance}

The results of the study are given in table. 4 and fig. 1 .

The data obtained show that initially cement samples are packed due to penetration into the body of cement the sulfate solution, formed ettringite crystals fill the pores, thereby increasing the strength of cement stone.

Since the porosity of the cement stone without additives is large the possibility of penetration of the ions $\mathrm{SO}_{4}{ }^{2-}$ is much more in comparison with the other samples. Accordingly mineral supplements reduce the negative impact of sulfate medium, especially 
zeolite tuff. Resistance coefficient of cement stone with the additives reaches 0.93 in comparison with $C_{R}=0.87$ cement without them.

Table 4. The strength of cement and resistance coefficient $C_{R}$

\begin{tabular}{|l|c|c|c|c|c|}
\hline \multirow{3}{*}{ Cement } & \multicolumn{5}{|c|}{ Compressive strength, MPa, at hardening } \\
\cline { 2 - 6 } & \multicolumn{3}{|c|}{ in water } & \multicolumn{2}{c|}{ in $5 \% \mathrm{Na}_{2} \mathrm{SO}_{4}$} \\
\cline { 2 - 6 } & $28 \mathrm{~d}$ & 3 month & 6 month & 3 month & 6 onth \\
\hline PC & 54.7 & 61.1 & 68.8 & 68.7 & 59.7 \\
\hline C-ZTVT & 54.0 & 62.3 & 71.5 & 65.5 & 64.4 \\
\hline C-ZT & 56.3 & 66.1 & 77.3 & 68.8 & 71.9 \\
\hline
\end{tabular}

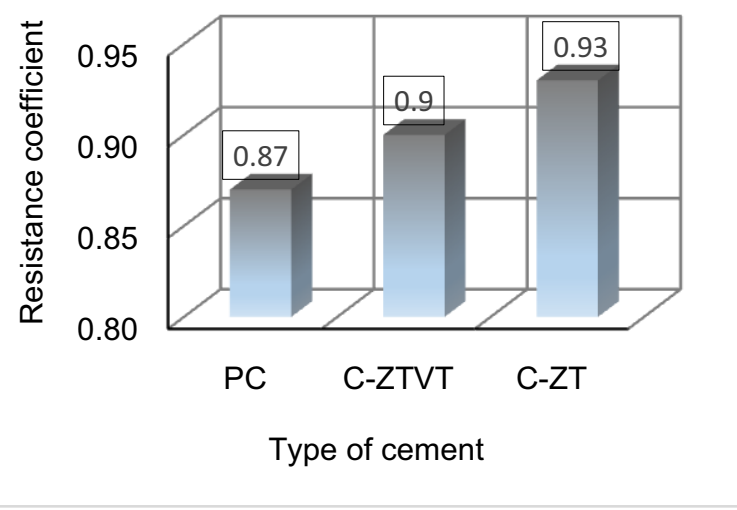

Fig. 1. $C_{R}$ after 6 month

\subsection{Frost resistance of cement stone}

Frost resistance of cement paste was evaluated by loss of strength and loss of mass of samples of cement. The results of the study are presented in fig. 2.

Tests of cement samples after 200 cycles of freezing and thawing showed that the their strength decreased slightly, and also a loss in weight of the samples and the cracks on their surfase are absent.

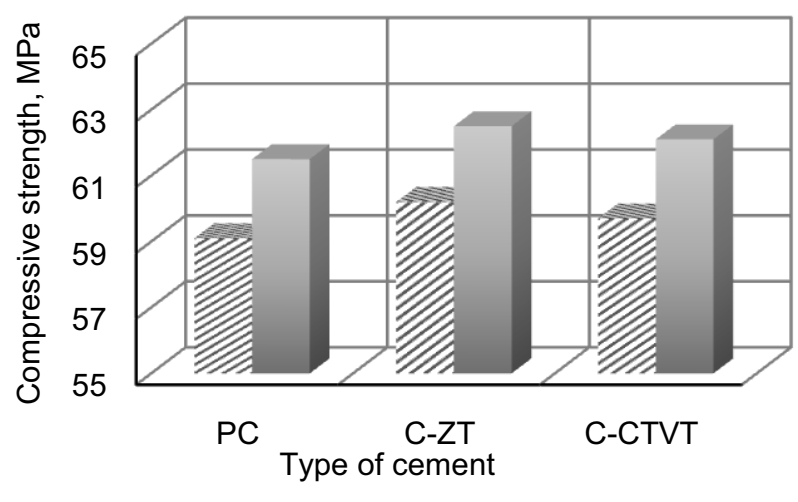

Fig. 2. Frost resistance of blended cements 
Thus, the frost resistance of cement with the additive zeolite tuff and his mix with volcanic tuff is not be deteriorated in comparison with Portland cement without additives.

\section{Conclusion}

The obtained results confirmed that zeolite tuff is characterized by high pozzolanicity activity. It promotes the consumption of $\mathrm{Ca}(\mathrm{OH})_{2}$, accelerates the cement hydration that leads to increase the strength of cement. Pozzolanic activity zeolite tuff allows simultaneously with it to use less active volcanic tuff as an additive of cement.

Combined usage of zeolite and volcanic tuffs as the additive for Portland cement leads to the increase of cement strength in long terms curing and provides high sulphate resistance and frost resistance of cement stone. The carried out studies allow us to recommend the investigated materials for the industrial production of cement. This will reduce the proportion of Portland cement clinker in the mixed cement, which will significantly reduce the energy consumption for its production and consequently improve the ecology of the environment due to the reduction of $\mathrm{CO}_{2}$ emissions into the atmosphere, which will contribute to the reduction of greenhouse gases.

\section{References}

1. R. Fernandez, F. Martirena, K.L. Scrivener. Cement and Concrete Research, 41, 4, 113-122 (2011)

2. A.P. Nefedev, Y.R. Krivoborodov, D.Y. Koccov. Proced. III Intern. Conference on concrete and reinforced concrete. Moscow, 6, 122-128 (2014)

3. E.N. Potapova, O.A. Golubev. Proced.III Intern. Conference on concrete and reinforced concrete. Moscow, 6, 129-136 (2014)

4. T.V. Kouznetsova, E.N. Potapova, A.C. Gorelik, M.V. Sidorova. Cement, 7, 22-23 (1989).

5. S.P. Sivkov, E.N. Potapova, C.A. Zaharov, D.V. Nazarov. Cement. Concrete. Dry mixes. Alitinform, 38, 1, 80-89 (2015)

6. S.V. Samchenko. 15 Intern. Daustofftagung, Weimar, 2,.2-1109-2-1114 (2003)

7. A.A. Kirsanova, L.Ya. Kramar. Stroitel'nyye materialy, 11.54-56 (2013)

8. T.V. Kuznetsova, Yu.R. Krivoborodov. Technology of concrete. 2 (91). 8-11 (2014)

9. R. Bucci. Proceedings of 8th International Congress on Cement Chemistry, Rio 1, 185-198 (1986)

10. 10 F.K. Mullick, H. Justnes, P. Fidjestol, S. Harsh. XIII Intern. Congress on Chemistry of Cement. Abstracts. Madrid, 45 (2011)

11. B.V. Gusev, In Yen-lan S., Y.R. Krivoborodov. XIV Intern. Congress on Chemistry of Cement. Peijing, (2015).

12. S.V. Samchenko, O.V. Zemskova, I.V. Kozlova. Technique and technology of silicates. 23, 2. S.19-23 (2016)

13. S.V. Samchenko. Proced. III Intern. Conference on concrete and reinforced concrete. Moscow, 6,137-143 (2014)

14. G.S. Royak, I.V. Granovskaya. International Conference, St. Petersburg, 117-120 (2007) 